\title{
Grupo Cuidar : Preparando Cuidadores
}

\author{
Paulin, Tathiane Andreia; Lima, Diego Pereira; Corradi, Maria Luiza Galoro; \\ Hayashibara, Julie Keiko \\ Hospital Geral de Carapicuíba — tathiane7@yahoo.com.br
}

Na enfermaria de Clínica Médica, do Hospital, existe uma grande complexidade das patologias que gera nos enfermos uma alta dependência em seus cuidados pessoais, mas com condições de receber alta hospitalar. Porém, o cuidador apresenta dúvidas e insegurança para receber o mesmo em sua residência, fazendo com que os índices de tempo médio de internação e readmissão hospitalar sejam altos. Diante das dificuldades observadas pela equipe multiprofissional que atua na enfermaria como falta de preparo dos cuidadores para receber o paciente, altas taxas de morbidades, mortalidade e readmissão, surgiu o "Grupo Cuidar". o Grupo proporciona um programa de orientação aos cuidadores dos pacientes de alta dependência, afim de esclarecer dúvidas, orientar, amenizar sua insegurança e prepará-lo para o cuidado domiciliar. Objetivo geral o "Grupo Cuidar" consiste num projeto multidisciplinar cujo objetivo é estabelecer medidas educativas e de capacitação técnica a leigos (agora denominados "cuidadores"), possibilitando-os auxiliar e dar assistência aos pacientes ditos "de alta dependência". Objetivos específicos Educar os cuidadores, tornando-os aptos a lidarem domiciliarmente com o paciente de alta dependência. Diminuir o tempo de permanência hospitalar. Diminuir a taxa de reinternação. Metodologia Semanalmente, o profissionais de diversar especialidades (Psicologia, Enfermagem, Fonoaudiologia, Fisioterapia, Farmácia e Nutrição) se reúnem com os cuidadores dos paciente de alta dependência de cuidados para uma aula. Nesse momento são explicados sobre cuidados com higiene pessoal, alimentação, cuidados com traqueostomia e exercícios, medicações e aspectos psíquicos do paciente e seu cuidador. Resultados alcançados Melhora da qualidade de vida dos pacientes Redução do tempo médio de internação Redução do índice de reinternação hospitalar. Estreitamento do vínculo entre equipe, paciente e familiar. Considerações finais: o Projeto Grupo Cuidar existe desde o início de 2011. Nesse período foram capacitados cerca de 200 cuidadores. Anterior à capacitação dos cuidadores, a média de reinternação dos pacientes até 30 dias da alta era de 3 pacientes por mês. Observou-se que após o início das aulas a média de reinternação é de um paciente.

Paulin, Tathiane Andreia; Lima, Diego Pereira; Corradi, Maria Luiza Galoro; Hayashibara, Julie Keiko. Grupo Cuidar : Preparando Cuidadores. In: Anais do Congresso Internacional de Humanidades \& Humanização em Saúde [= Blucher Medical Proceedings, num.2, vol.1]. São Paulo: Editora Blucher, 2014. ISSN 2357-7282

DOI 10.5151/medpro-cihhs-10576 